GRASAS Y ACEITES 69 (1)

January-March 2018, e238

ISSN-L: 0017-3495

https://doi.org/10.3989/gya.0994171

\title{
Effect of carotenoids, extracted from dry tomato waste, on the stability and characteristics of various vegetable oils
}

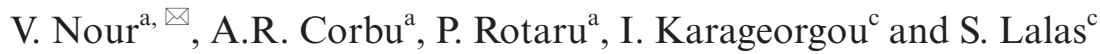 \\ ${ }^{a}$ Department of Horticulture \& Food Science, University of Craiova, Romania \\ ${ }^{b}$ Department of Physics, University of Craiova, Romania \\ ${ }^{c}$ Department of Food Technology, Technological Educational Institution of Thessaly, Karditsa, Greece \\ Corresponding author: vionor@yahoo.com
}

Submitted: 23 September 2017; Accepted: 30 November 2017

SUMMARY: In this study, various vegetable oils were enriched with carotenoids originating from dry tomato waste using ultrasound-assisted extraction, microwave-assisted extraction and maceration. Analyses of total carotenoids, color and oxidative stability (determined by free radical scavenger activity, peroxide value, Rancimat method and DSC analysis) were carried out. Commercial oils without enrichment were used for comparison. The results showed that the carotenoid contents of the oils increased significantly by increasing incorporation of dry tomato waste. Also, maceration proved to extract significantly higher amounts of these compounds. In some oils the extraction of dry tomato waste improved their oxidative and thermal stability while in others it caused an increase in the peroxide value and a decrease in induction time. Finally, the color parameters of the oils were significantly influenced. Enriched oils could be a potential source of bioactive compounds and might have significant antioxidant activity when ingested as part of a dietary regime.

KEYWORDS: Carotenoids; Color; Extraction; Oxidative Stability; Tomato waste; Vegetable oils

RESUMEN: Efecto de los carotenoides, extraídos de residuos de tomates secos, sobre la estabilidad y características de aceites vegetales. En este estudio varios aceites vegetales se enriquecieron con carotenoides obtenidos a partir de residuos de tomates secos utilizando extracción asistida por ultrasonido, extracción asistida por microondas y maceración. Se llevó a cabo un análisis de los carotenoides totales, el color y la estabilidad oxidativa (determinada por la actividad captadora de radicales libres, el índice de peróxidos, el método Rancimat y el análisis DSC). Los aceites comerciales sin enriquecimiento se usaron como testigos. Los resultados mostraron que el contenido de carotenoides de los aceites aumentó significativamente al aumentar la incorporación de residuos secos de tomate. Además, la maceración demostró extraer cantidades significativamente más altas de estos compuestos. En algunos aceites, el residuo seco de tomates mejoró su estabilidad oxidativa y térmica, mientras que en otros causó un aumento en el índice de peróxido y una disminución en el tiempo de inducción. Finalmente, los parámetros de color de los aceites se vieron significativamente influenciados. Los aceites enriquecidos podrían ser una fuente potencial de compuestos bioactivos y podrían tener una actividad antioxidante significativa cuando se ingieren como parte de un régimen dietético.

PALABRAS CLAVE: Aceites vegetales; Carotenoides; Color; Estabilidad oxidativa; Extracción; Desechos de tomates

ORCID ID: Nour V https://orcid.org/0000-0001-9904-0157, Corbu AR https://orcid.org/0000-0002-6859-1981, Rotaru P https://orcid.org/0000-0003-3430-8073, Karageorgou I https://orcid.org/0000-0003-1639-0106, Lalas S https://orcid. org/0000-0002-6825-7350

Citation/Cómo citar este artículo: Nour V, Corbu AR, Rotaru P, Karageorgou I, Lalas S. 2108. Effect of carotenoids, extracted from dry tomato waste, on the stability and characteristics of various vegetable oils. Grasas Aceites 69 (1), e238. https://doi.org/10.3989/gya.0994171

Copyright: (C2018 CSIC. This is an open-access article distributed under the terms of the Creative Commons Attribution 4.0 International (CC BY 4.0) License. 


\section{INTRODUCTION}

Carotenoids are one of the most important groups of natural pigments which provide the yellow, orange, and red colors to fruits, vegetables, plants, and marine animals (Zhao et al., 2006). Carotenoids are very efficient physical quenchers of singlet oxygen and scavengers of other reactive oxygen species. They can also act as chemical quenchers, undergoing irreversible oxygenation. Epidemiological studies and clinical trials have shown that adequate carotenoid supplementation may significantly reduce the risk of several disorders mediated by reactive oxygen species such as certain types of cancer or cardiovascular diseases (Fiedor and Burda, 2014).

Tomatoes and tomato products contain carotenoids in high amounts (around 5.1-6.3 mg/100 g fresh weight), the main constituent being lycopene $(70-80 \%)$, which provides the tomato fruit with its intense red color (Vagi et al., 2007). After tomatoes are processed, $3-7 \%$ of their weight becomes waste which consists of skins, pulp and seeds, which are typically used as ingredients in animal feed or even discarded in many cases. The by-products of tomato processing are one of the most promising sources of antioxidant compounds. The tomato peels have been found to be richer sources of phenolic compounds, lycopene, ascorbic acid and antioxidant activity compared to their pulp and seed fractions (Toor and Savage, 2005). In addition, tomato seeds are rich in nutrients such as carotenoids, proteins, polyphenols, minerals, fibers and oil (Zuorro et al., 2013).

The extraction of lycopene and $\beta$-carotene from tomato by-products is attracting worldwide interest in order to use them as food colorants, functional food ingredients, or as components of dietary supplements. A number of techniques have been used to extract $\beta$-carotene and other carotenoids from plant materials. Apart from conventional extraction methods such as stirring extraction and Soxhlet extraction, which are generally time-consuming and laborious, various novel techniques are available for the extraction of natural antioxidants from plant materials, including ultrasound-assisted extraction (UAE), microwave-assisted extraction (MAE) and supercritical fluid extraction (Huang et al., 2009). Both MAE and UAE could accelerate the extraction process and this may improve bioactive compound extraction (Lianfu and Zelong, 2008). In order to avoid solvents of petrochemical origin, the industry is tending towards the use of more environmentally benign alternative solvents. In addition, some food scientists have proposed avoiding extraction by recycling the raw or dried lycopene rich by-products directly as food ingredients. A functional food oil, rich in fatty acids and antioxidants, colored with pigments (carotenoids) extracted with supercritical
$\mathrm{CO}_{2}$ from the microalga Chlorella vulgaris, was produced by Gouveia et al., (2007), with a view for its use in the food industry. Benakmoum et al., (2008) proposed to enrich refined olive oil and refined sunflower oil with carotenoids and lycopene from tomato peels or tomato puree in order to increase the thermal stability of these oils. Sunflower oil was applied as a substitute for organic solvents in a green ultrasound-assisted extraction of carotenoids from fresh carrots ( $\mathrm{Li}$ et al., 2013) while Zuorro et al., (2013) produced a lycopene-enriched oil by incorporating a tomato oleoresin derived from tomato peels in oil obtained by cold pressing of the tomato seeds.

Vegetable oils are natural products obtained from oil-containing seeds, fruits, or nuts by different pressing methods, solvent extraction or a combination of these. Although vegetable oils naturally contain antioxidants such as tocopherols, tocotrienols, carotenoids, phenolic compounds, and sterols, they lack sufficient oxidative stability. The oxidation of oil destroys essential fatty acids and produces lowmolecular weight off-flavor compounds, toxic compounds and oxidized polymers which can cause changes in the sensory and technological properties of the oil, reducing its shelf-life, and making the oil less acceptable to consumers or for industrial use (Choe and Min, 2006). In order to overcome the stability problems of oils and fats, synthetic antioxidants, such as butylated hydroxytoluene (BHT) and butylated hydroxyanisole (BHA), are added to oils due to their high efficiency, high stability and low cost. However, recent reports reveal that these compounds may have adverse health effects on humans exposed to them, including the promotion of cancer and carcinogenesis (Bouayed and Bohn, 2010). Therefore, the search for natural replacements for conventional synthetic antioxidants is now becoming an increasing trend among food scientists. Several studies have been conducted in recent years on the enrichment of oils with sources of natural antioxidants from plant species which are seen to possess antioxidant properties. Rosemary extracts in walnut oil (Martínez et al., 2013) and in sunflower oil (Zhang et al., 2010), olive leaf and tea extracts in soybean oil (Malheiro et al., 2013) and avocado and olive leaf extracts in edible oils (Jiménez et al., 2017) have shown to exert various degrees of antioxidant activity. The activity of these plant extracts has been attributed to the presence of flavonoid compounds, phospholipids, tocopherols, and ascorbic acid (Tsaknis and Lalas, 2005). The antioxidant compounds from residual sources could also be used for increasing the stability of vegetable oils (Mirabella et al., 2014). Studies to incorporate the crude extracts or the whole vegetable material of residual origin in oils as antioxidant ingredients are scarce.

In this work, various vegetable oils were used as alternative solvents in order to obtain oils enriched 
in carotenoids intended to be used in various food applications. Comparative studies among maceration, UAE and MAE were carried out in terms of total carotenoid content, color and oxidative stability of the resulting oils.

\section{MATERIALS AND METHODS}

\subsection{Materials and reagents}

The tomato waste, containing the skin and seeds of ripe tomato, was obtained from Elio Monte Verde, a tomato-processing unit in Caracal, Romania. Twenty kilograms of tomato waste were collected, air-dried in a tray dryer (Memmert, Germany) at $60{ }^{\circ} \mathrm{C}$, mixed well and then ground to a powder to pass through a $0.70 \mathrm{~mm}$ sieve, packed in aluminum coated polyethylene bags and stored in ambient conditions for further analysis and use.

Moisture, total carotenoids, total phenolics, minerals and trace element contents as well as the antioxidant activity of the tomato waste powder were determined in triplicate.

Ten different vegetable oils were used, namely extra virgin sunflower oil "Bonsana" (VIRGINOIL S.R.L., Bacau, Romania), unrefined corn oil "Arpis" (MAN RO S.R.L., Satu-Mare, Romania), refined rapeseed oil "Argus" (ARGUS S.A., Constanta, Romania), extra virgin olive oil "Spartans" (AMVROSIA TAP FOODS, Kallithea, Greece), olive pomace oil "Ondoliva" (ONDOLIVA, Spain), soybean oil "VALSOIA" (VALSOIA S.p.a., Bologna, Italy), refined sunflower oil "Surasul soarelui" (PRUTUL S.A., Galati, Romania), peanut oil (LESIEUR, Bordeaux, France), rice oil "Dr. Scotti" (RISO SCOTTI S.P.A., Pavia, Italy), grape seed oil "Costa d'Oro Vinacciolo" (COSTA D'ORO S.p.A., Spoleto, Italy). All the oils were obtained from a local supermarket.

Analytical grade reagents (Sigma Aldrich, Germany) were used for analyses. Sodium carbonate, Folin-Ciocalteu's phenol reagent, and DPPH (1,1-diphenyl-2-picrylhydrazyl) were obtained from Sigma-Aldrich (Germany). All solvents used were of analytical grade and purchased from Merck (Germany).

\subsection{Sample preparation}

Three experiments were conducted to investigate the influence of the type of oil, the extraction method and the dried tomato waste concentration on the recovery of carotenoids and oxidative stability of the edible vegetable oils enriched in carotenoids from dried tomato by-products.

In the first, ground dried waste samples were subjected to ultrasound-assisted extraction at 5\% (w/v) concentration in extra virgin sunflower oil, unrefined corn oil, refined rapeseed oil, extra virgin olive oil, olive pomace oil, soybean oil, refined sunflower oil, peanut oil, rice oil and grape seed oil at $20{ }^{\circ} \mathrm{C}$ for $50 \mathrm{~min}$.

A second experiment was conducted to assess the influence of the extraction method. Triplicate dried waste samples $(5 \mathrm{~g})$ were subjected to each of the following extraction procedures: (a) ultrasound-assisted extraction in $100 \mathrm{~mL}$ oil at $20{ }^{\circ} \mathrm{C}$ for $50 \mathrm{~min}$; (b) microwave-assisted extraction in 100 $\mathrm{mL}$ oil for $5 \mathrm{~min}$; (c) maceration at $20^{\circ} \mathrm{C}$ in $100 \mathrm{~mL}$ oil for 7 days. Extra virgin sunflower oil, unrefined corn oil and refined rapeseed oil were tested in this experiment.

The ultrasound-assisted extractions were carried out during $50 \mathrm{~min}$ in a Bandelin Sonorex Digital 10P ultrasound bath (Bandelin Electronic $\mathrm{GmbH}$, Berlin, Germany) operating at $35 \mathrm{kHz}$ with $480 \mathrm{~W}$ power. The temperature was controlled and maintained at $20^{\circ} \mathrm{C}$ by periodically replacing the water in the bath with cold water.

Microwave-assisted extractions were performed using a domestic microwave oven (Samsung model 9245, MB245), with $2450 \mathrm{MHz}$ working frequency at a constant microwave power of $700 \mathrm{~W}$. At the end of the microwave irradiation, the samples were allowed to cool to room temperature.

In the third experiment, ground dried waste samples were applied to commercial extra virgin sunflower oil, unrefined corn oil and refined rapeseed oil at different concentrations $(2.5,5,10$ and $20 \%$, $\mathrm{w} / \mathrm{v}$ ) and subjected to ultrasound-assisted extraction at $20^{\circ} \mathrm{C}$ for $50 \mathrm{~min}$. Each experiment was conducted three times.

All the extractions were followed by filtration through Whatman No.1 filter paper and the resulting oils were collected in screw-capped dark plastic containers completely filled with oil and stored at $4{ }^{\circ} \mathrm{C}$ until they were analyzed. The commercial oils were also stored under the same conditions as the enriched oils to be used as blanks for all the tests. The oils were sampled for each measurement from separate bottles.

\subsection{Determination of total carotenoids}

Carotenoid extraction was adapted from that described by Taungbodhitham et al., (1998). $3 \mathrm{~g}$ of oil were stirred for $5 \mathrm{~min}$ with $80 \mathrm{mg}$ of $\mathrm{MgCO}_{3}$ and $15 \mathrm{~mL}$ of extraction solvent (ethanol/ hexane, $4: 3(\mathrm{v} / \mathrm{v})$, containing $0.1 \%$ of BHT as antioxidant). The residue was separated from the liquid phase by filtration with a filter funnel (porosity no. 2) and washed with $15 \mathrm{~mL}$ of ethanol and $30 \mathrm{~mL}$ of hexane. Organic phases were transferred to a separatory funnel and successively washed with $50 \mathrm{~mL}$ of $10 \%$ sodium chloride and $3 \times 50 \mathrm{~mL}$ distilled water. The aqueous layer was removed. The hexanic phase was dried under anhydrous sodium sulphate, filtered and 
evaporated to dryness at $40{ }^{\circ} \mathrm{C}$ in a rotary evaporator. The residue was dissolved in $500 \mu \mathrm{L}$ of dichloromethane and $500 \mu \mathrm{L}$ of MTBE/methanol (80/20, $\mathrm{v} / \mathrm{v})$. Samples were placed in amber vials before HPLC analysis. The saponification was carried out in $10 \%$ methanolic $\mathrm{KOH}$, according to the method described by Fanciullino et al., (2006).

Total carotenoids were determined according to the method described by Katsoyannos et al., (2012) using a Shimadzu CBM-20A (Shimadzu Europa $\mathrm{GmbH}$, Germany) liquid chromatograph equipped with a SIL-20AC auto sampler and a CTO-20AC column oven. Detection was carried out using a Shimadzu SPD-M20A diode array detector set at $450 \mathrm{~nm}$. The column used was a Phenomenex Luna C18(2), (100 ̊, $5 \mu \mathrm{m}, 4.6 \times 250 \mathrm{~mm})$ (Phenomenex, Inc., USA).

\subsection{Determination of peroxide value}

The oils were tested for their antioxidant activity using the UV accelerated method as described by Lalas and Tsaknis (2002). Ten grams of each oil sample were accurately weighed into a glass Petri dish (87 $\mathrm{mm}$ i.d. and $15 \mathrm{~mm}$ high). The dishes were directly exposed to UV light produced by a lamp situated $50 \mathrm{~cm}$ above (General Electric $260 \mathrm{~nm}$ UV Germicidal lamp G25T8, 25 watt, $45 \mathrm{~cm}$ in length, and $3 \mathrm{~cm}$ in diameter) for $12 \mathrm{~h}$. The extent of oxidation of the oils after $12 \mathrm{~h}$ of oxidation was assessed using peroxide value (PV). The method used for the determination of PV is based on iodometric titration, which measures the iodine produced from potassium iodide by the peroxides present in the oil.

In a stopper conical flask $(250 \mathrm{~mL})$ one gram of vegetable oil was taken along with chloroform (10 $\mathrm{mL})$ and glacial acetic acid $(15 \mathrm{~mL})$. One milliliter of saturated potassium iodide was then added. The flask was stoppered and shaken vigorously for $1 \mathrm{~min}$ and then kept in the dark for a further $10 \mathrm{~min}$. Then, double distilled water $(100 \mathrm{~mL})$ was mixed thoroughly with the solution and the liberated iodine was titrated until colorless with a $0.01 \mathrm{~N}$ sodium thiosulfate solution, adding a $1 \%$ starch solution as an indicator. A blank run was performed omitting the oil, and the peroxide value was calculated as miliequivalents (meq) peroxide oxygen per $\mathrm{kg}$ of oil using the following formula:

$\mathrm{PV}(\mathrm{meq} / \mathrm{kg})=(\mathrm{S}-\mathrm{B}) \times \mathrm{F} \times \mathrm{N} \times 1000 / \mathrm{W}$ where $\mathrm{S}$ : titration amount of sample, $\mathrm{B}$ : titration amount of blank, F: titer of $0.01 \mathrm{~N} \mathrm{Na}_{2} \mathrm{~S}_{2} \mathrm{O}_{3}, \mathrm{~N}$ : normality of $\mathrm{Na}_{2} \mathrm{~S}_{2} \mathrm{O}_{3}, \mathrm{~W}$ : sample weight ( $\left.\mathrm{g}\right)$.

\subsection{Determination of free radical scavenger activity}

The oil samples were analyzed for their capacity to scavenge the stable 2,2-diphenyl-1-picrylhydrazyl radical (DPPH) (Kalantzakis et al., 2006). One milliliter of a solution containing $0.5 \mathrm{~g}$ of oil in $5 \mathrm{~mL}$ of ethyl acetate were added to $4 \mathrm{~mL}$ of a freshly prepared DPPH solution (10-4 M in ethyl acetate) in a screw-capped $10 \mathrm{~mL}$ test tube. The reaction mixture was shaken vigorously for $10 \mathrm{~s}$ in a Vortex apparatus and the tube was maintained in the dark for $30 \mathrm{~min}$ so as to reach steady-state stability. The absorbance of the mixture was measured at $515 \mathrm{~nm}$ against a blank solution (without radical). Meanwhile, a control sample containing $1 \mathrm{~mL}$ of ethyl acetate and $4 \mathrm{~mL}$ of the DPPH solution was prepared and equally measured. The radical scavenging activity towards DPPH was expressed as the $\%$ reduction in DPPH concentration by the constituents of the oils: $\%[\mathrm{DPPH}] \mathrm{red}=100 \times$ $(1-[\mathrm{DPPH}] 30 /[\mathrm{DPPH}] 0)$, where $[\mathrm{DPPH}] 0$ and [DPPH] 30 were the concentrations of DPPH in the control sample $(\mathrm{t}=0)$ and in the test mixture after the 30 min reaction, respectively.

\subsection{Determination of susceptibility to oxidation}

The susceptibility to oxidation of the oils was determined using the Rancimat method and was expressed as induction period. The determinations were carried out using the method described by Lalas and Dourtoglou, (2003). Three grams of oil were accurately weighed into each of the reaction vessels of the Rancimat 743 (Metrhom LTD, Herisau, Switzerland). The temperature was set at 90 ${ }^{\circ} \mathrm{C}$ and the airflow rate at $15 \mathrm{~L} / \mathrm{h}$. During the oxidation process, the volatile acids formed in the distilled water were measured conductimetrically. The induction period is the time required by the conductivity curve to reach the inflection point. The induction period of a sample of the corresponding control oil was used for comparison. The antioxidant activity of carotenoids extracted from tomato waste was evaluated using the protection factor (PF) which was calculated as the ratio between the induction period of the enriched oil and the induction period of the control (unenriched oil). PF values $>1$ show antioxidant behavior, whereas $\mathrm{PF}$ values $<1$ suggest a pro-oxidant activity. The higher the protection factor value, the better the antioxidant activity.

\subsection{Thermal analysis}

Thermal analysis of oil samples (extra virgin sunflower and extra virgin sunflower oil enriched in carotenoids after extraction of dry tomato waste) was performed with a horizontal hermos-balance DIAMOND TG/DTA Analyzer from PerkinElmer Instruments, in a dynamic air atmosphere (150 $\left.\mathrm{cm}^{3} \cdot \mathrm{min}^{-1}\right)$, under non-isothermal linear regime, at a constant heating rate of $10 \mathrm{~K} \mathrm{~min}^{-1}$. The weight change (TG), its rate (DTG) as well as the difference in the heat flow rate between the sample and the reference material (DSC) were registered simultaneously. The thermoanalytical curves were 
recorded as a function of temperature. During this determination, the temperature was set from room temperature to $600{ }^{\circ} \mathrm{C}$. Samples were placed in aluminum crucibles. The results were processed and graphically represented using the dedicated Pyris Software, from PerkinElmer Instruments. The thermal stability was measured from the extrapolated onset temperature of the first step of thermal decomposition from respective TG curves. The heat of combustion was estimated from the total area of the exothermal DSC peaks of the thermal decomposition of each oil, which occurred during the analysis.

\subsection{Color}

After extraction, the oils were filtered through filter paper and kept in glass bottles in total darkness until the color measurements took place.

Color change was examined by visual inspection and quantified using the CIE (Commission internationale de l'éclairage, 1976) $\left(\mathrm{L}^{*} \mathrm{a} * \mathrm{~b}\right)$ system. The CieLab coordinates $\left(L^{*}, a^{*}, b^{*}\right)$ were directly read with a Thermo Scientific Evolution 600 UV/ vis spectrophotometer, calibrated with a white tile. In this coordinate system, the $\mathrm{L}^{*}$ value is a measure of lightness, ranging from 0 (black) to 100 (white), the $\mathrm{a}^{*}$ value represents the red/green axis and varies from -100 (greenness) to +100 (redness) and the $b^{*}$ value represents the yellow/blue axis and ranges from -100 (blueness) to +100 (yellowness). Three readings were taken for each sample.

\subsection{Statystical analysis}

The determinations were made in triplicate. The values of different parameters were expressed as mean \pm standard deviation. Data were subjected to analysis of variance (ANOVA), and the significance of differences between means was assessed by Duncan's multiple range test at $p<0.05$. All statistical analyses were performed using Statgraphics Centurion XVI software (StatPoint Technologies, VA, USA).

\section{RESULTS AND DISCUSSION}

\subsection{Carotenoid contents of the oils}

Before extraction, the highest carotenoid content was determined in grape seed oil $(16.7 \mathrm{mg} / \mathrm{kg})$, followed by unrefined corn oil $(6.1 \mathrm{mg} / \mathrm{kg})$. Lower levels were found in soybean oil $(3.3 \mathrm{mg} / \mathrm{kg})$, extra virgin olive oil $(2.1 \mathrm{mg} / \mathrm{kg})$ and extra virgin sunflower oil $(1.6 \mathrm{mg} / \mathrm{kg})$ while carotenoids were not detected in the refined oils of rapeseed, sunflower, olive pomace, peanut or rice (Table 1).

During the experiments, a significant increase in carotenoid content was observed in the oils after the extraction of dry tomato waste. The increase in carotenoid content after the extraction of 5\% tomato waste was found between $29.2 \mathrm{mg} / \mathrm{kg}$ and $38.0 \mathrm{mg} / \mathrm{kg}$, reflecting the solubility of carotenoids in these oils (Table 1). The highest solubility was recorded in extra virgin olive oil, followed by rice oil. Benakmoum et al., (2008) reported that the carotenoid solubility in oils increased when the chain-length of the triglyceride fatty acids decreased while there was no effect of the fatty acid unsaturation degree on carotenoid solubility.

The extraction method significantly influenced the quantity of carotenoids extracted in oil (Table 2). For all three tested oils, the highest amount of carotenoids was extracted by soaking for 7 days, followed by the UAE and MAE. Nevertheless, these methods take less time, affording a good extraction at lower costs. The enhancement in extraction obtained by using ultrasound is mainly attributed to the acceleration of the mass transfer as a result of the acoustic cavitations produced in the solvent by the passage of an ultrasound wave. Ultrasound allows greater penetration of solvent into the sample matrix by disrupting the plant cell wall and facilitating the solvent access to the cell content and the release of the extractable compounds (Li et al., 2013). Microwaveassisted extraction determines a faster heating and accelerates the extraction process for adsorption and desorption of the targeted compounds from the matrix (Lianfu and Zelong, 2008). The carotenoid content of the oils increased significantly by increasing the incorporation of dry tomato waste (Table 3 ). Furthermore, linear dependencies were found between the content of carotenoids in the enriched oils and the amount of waste extracted, with coefficients of determination $\mathrm{R}^{2}$ of $0.995,0.989$ and 0.999 for extra virgin sunflower oil, unrefined corn oil and refined rapeseed oil, respectively.

\subsection{Oxidative stability}

Rice oil showed the lowest peroxide value (5.9 meq $\mathrm{O}_{2} / \mathrm{kg}$ ) (Table 1). This oil contains high levels of phytosterols, gamma-oryzanol, tocotrienols and tocopherols (Gopala Krishna et al., 2005) which impart a high resistance to oxidation and deterioration of the oil.

The highest peroxide value was found for extra virgin sunflower oil ( 183.0 meq $\mathrm{O}_{2} / \mathrm{kg}$ ); while refined sunflower oil also reached a high peroxide value of $96.1 \mathrm{meq} \mathrm{O}_{2} / \mathrm{kg}$. Previous studies reported that the rate of peroxide formation in sunflower oil is markedly higher than those in other oils and they attributed this to the tocopherol type predominating in the tocopherol composition of the oils. Sunflower oil contains principally alpha-tocopherol, which exhibits the lowest antioxidation activity while soybean oil contains high antioxidation potency tocopherols (gamma- and delta-tocopherols) (Hassanein 


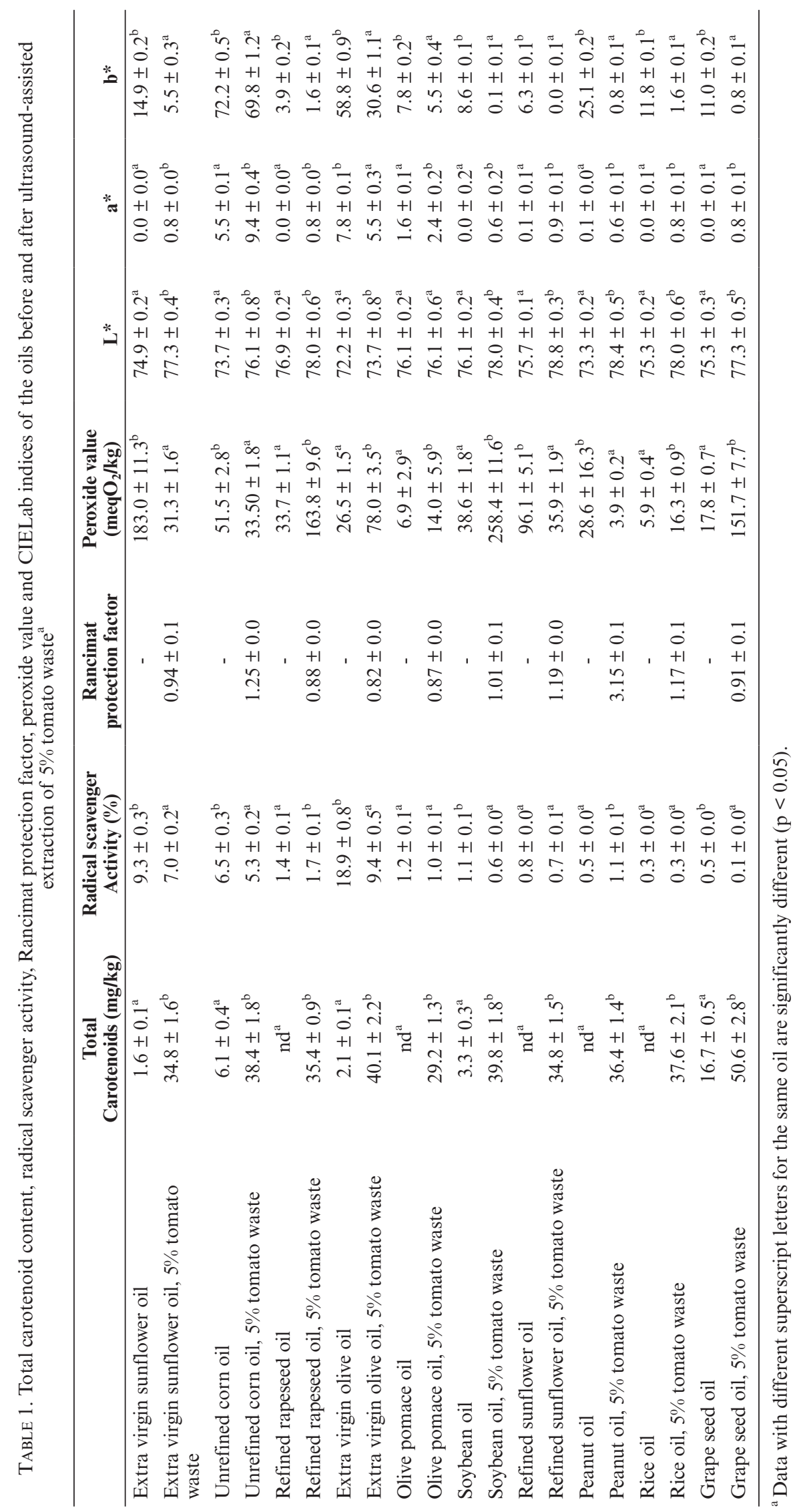




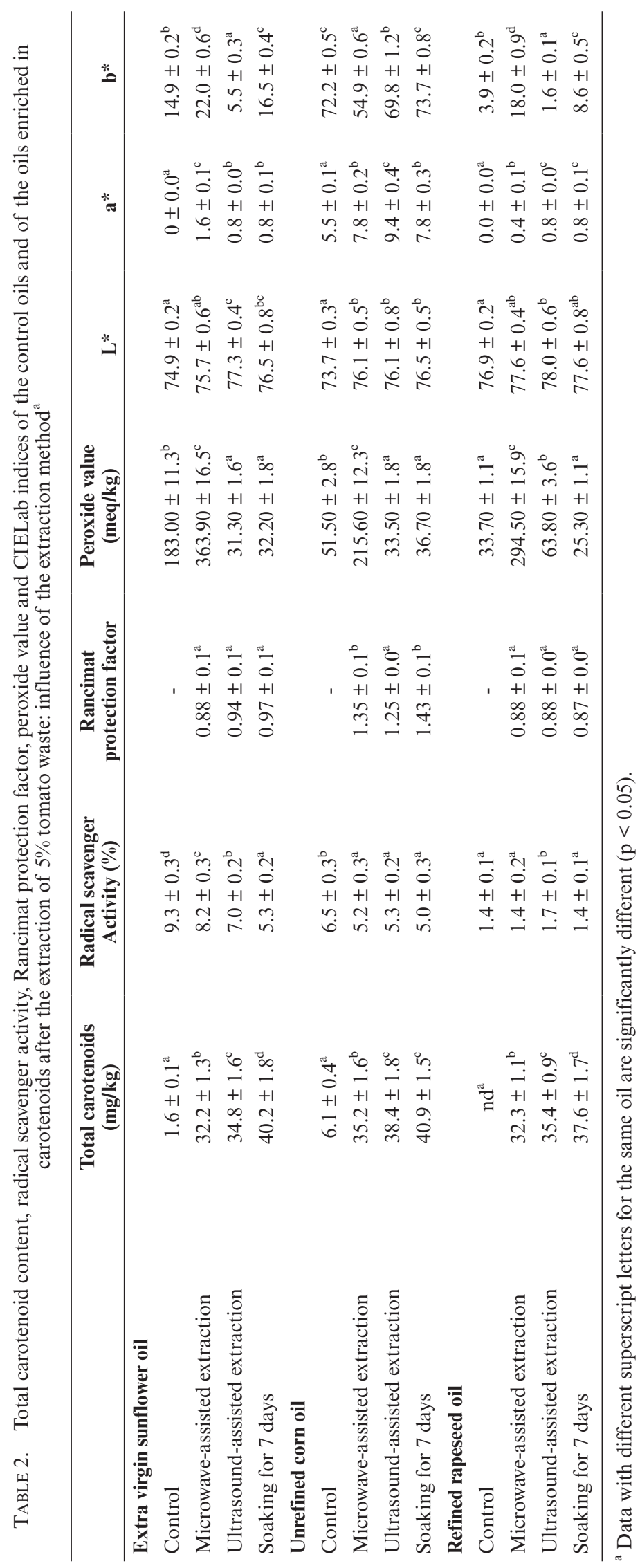

Grasas Aceites 69 (1), January-March 2018, e238. ISSN-L: 0017-3495 https://doi.org/10.3989/gya.0994171 


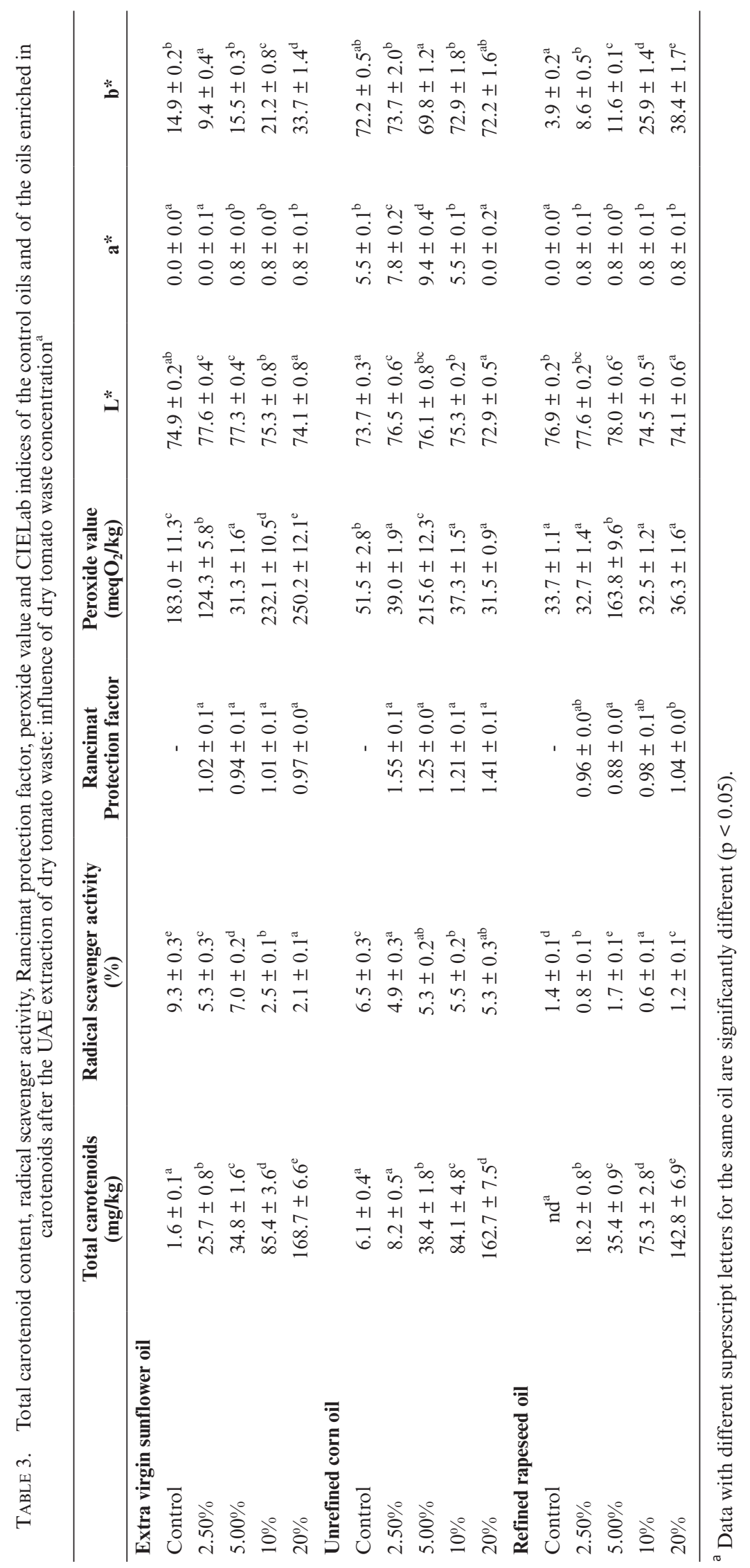


et al., 2003). In addition, sunflower and corn oils are oxidized more easily and rapidly as they are rich in polyunsaturated fatty acids. The extra virgin and pomace olive oils showed lower peroxide values $(26.5$ and $6.9 \mathrm{meq} \mathrm{O}_{2} / \mathrm{kg}$ respectively) as they contain high amounts of the monounsaturated fatty acid oleic acid and they are particularly rich in phenolic antioxidants (Choe and Min, 2006; Cheung et al., 2007).

The extraction of carotenoids from dry tomato waste led to significant but contradictory changes in peroxide value. While the refined rapeseed oil, the extra virgin olive oil, the soybean oil and the grape seed oil showed significant increases in their peroxide values after the UAE extraction of 5\% tomato waste, there were significant decreases in the peroxide value for extra virgin sunflower oil, unrefined corn oil, refined sunflower oil and peanut oil. According to previous studies these contradictory changes in the peroxide value could be assigned to the antioxidant or pro-oxidant behavior of carotenoids that occurs in certain conditions. Carotenoids could increase the hydroperoxide formation of autoxidized triglycerides, this pro-oxidant activity of carotenoids being related to the oxygen concentration, the chemical structure of carotenoids and the presence of other antioxidants such as polyphenols and tocopherols (Shixian et al., 2005), compounds that are extracted along with carotenoids from dry tomato waste. Not only carotenoids, but also other antioxidants are beneficial in terms of improving oxidative stability only up to a point, with the increased loading of antioxidants determining a pro-oxidant effect (Moure $e t$ al., 2001). For example, in a study on the effects of tocopherols on the oxidative stability of soybean oil, Jung and Min, (1990) reported that concentrations of tocopherols higher than what was determined as optimum resulted in pro-oxidant effects.

Extra virgin sunflower oil, unrefined corn oil and refined rapeseed oil enriched in carotenoids by ultrasound assisted extraction or by soaking of $5 \%$ dry tomato waste presented lower peroxide values as compared with the control oils (Table 2). A much higher peroxide value (2 to 8.7 times higher) was found for the oils enriched in carotenoids by the MAE of dry tomato waste. These results were expected because it is well known that heating by microwave energy accelerates lipid oxidation. The highest peroxide value was found for the extra virgin sunflower oil enriched in carotenoids by the MAE of dry tomato waste, a fact that is in agreement with the highest content of polyunsaturated fatty acids of this oil among the three investigated oils. Hassanein et al., (2003) also reported that in vegetable oils exposed to microwave energy, the higher the oil content in polyunsaturated fatty acids, the greater the rate of oils' quality deterioration.

In most oils, the extraction of dry tomato waste resulted in a slight but significant decrease in the radical scavenger activity, suggesting again that the extracted compounds could possess a pro-oxidant activity.

Table 1 presents the changes in the induction period of the control oils after the extraction of dry tomato waste. Among the investigated oils, olive oil samples presented a longer period of induction, which is in agreement with previous findings and related to some extent to the presence of $\alpha$-tocopherol and phenolic compounds (Lalas et $a l ., 2007)$. Grape seed oil showed the lowest induction period because of the high content in polyunsaturated fatty acids, which is in accordance with the findings of Juliano et al. (2005).

The results showed that the extraction of carotenoids from dry tomato waste improved the stability of some oils (unrefined corn oil, refined sunflower oil and peanut oil). In these cases, the induction periods of the extracted oils appeared to be significantly higher than those of the control oils. However, in most investigated oils the stability of oil decreased after the extraction of carotenoids from dry tomato waste or there were no significant differences between the induction period of the control oil and of the oil enriched in carotenoids. Moreover, as can be seen in Table 3, increasing the addition of dry tomato waste had no significant influence on the induction time.

In a previous study, Benakmoum et al., (2008) reported that induction times increased by 2.1 times by incorporating 30\% tomato puree and by 1.4 times by incorporating 10\% tomato peel in refined olive oil; while they decreased by adding tomato puree in virgin olive oil and sunflower oil to 0.7 and 0.4 times the initial induction times. The Rancimat method is carried out at elevated temperatures and with a high flow of air (oxygen). This may lead to a much higher decomposition of some compounds (i.e. carotenoids).

\subsection{Thermal analysis}

The thermal stability of the oils was investigated using a dynamic DSC method under air atmosphere. Figure 1 shows the TG, DTG and DSC curves of extra virgin sunflower oil while figure 2 presents the thermoanalytical curves of extra virgin sunflower oil enriched in carotenoids after the extraction of dry tomato waste. These curves indicate the total absence of metals, the lack of water and of volatile liquids in samples and good thermal stability. Both samples were completely decomposed in the oxidative ambient of air flow with no residue remaining at $550{ }^{\circ} \mathrm{C}$.

The comparative analysis of the thermogravimetric curves shows that sunflower oil was thermally stable up to $206{ }^{\circ} \mathrm{C}$, while the oil enriched in carotenoids after extraction has been thermally stable only up to $177{ }^{\circ} \mathrm{C}$. Up to $250{ }^{\circ} \mathrm{C}$ sunflower oil enriched in carotenoids lost $7.0 \%$ of its initial 


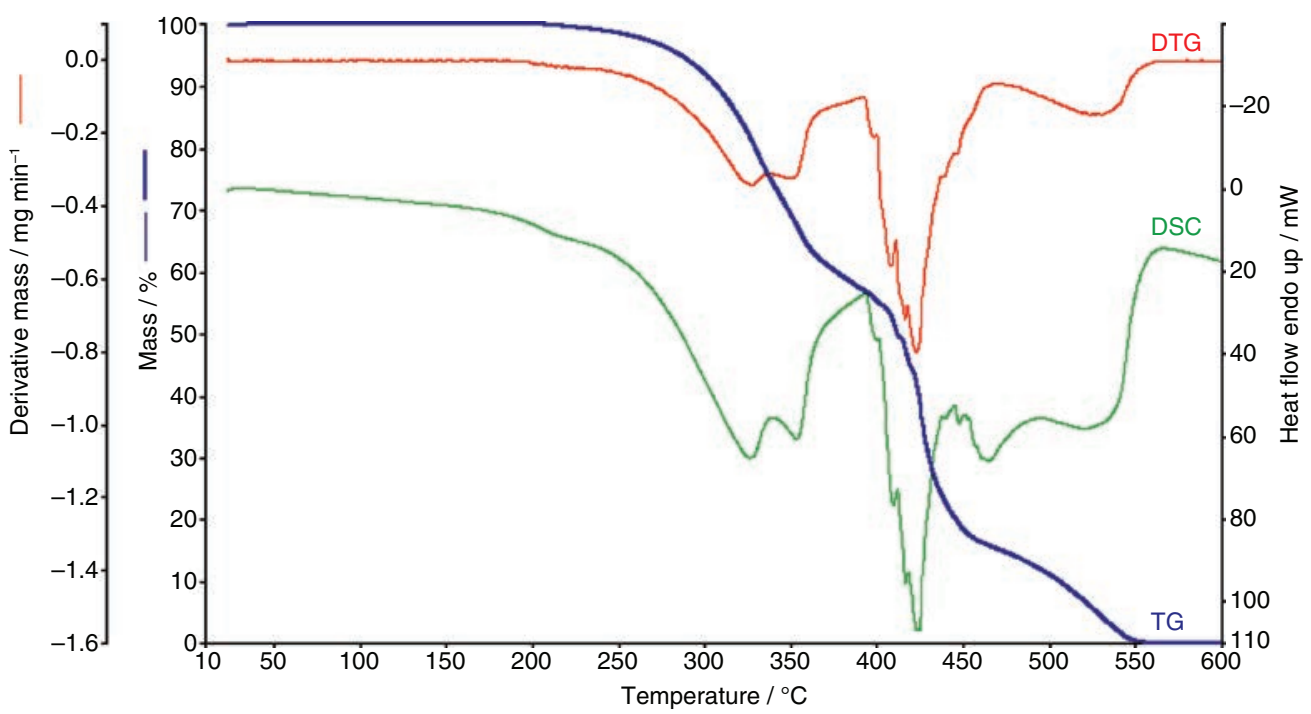

FIGURE 1. Thermoanalytical (TG, DTG and DSC) curves of control sunflower oil.

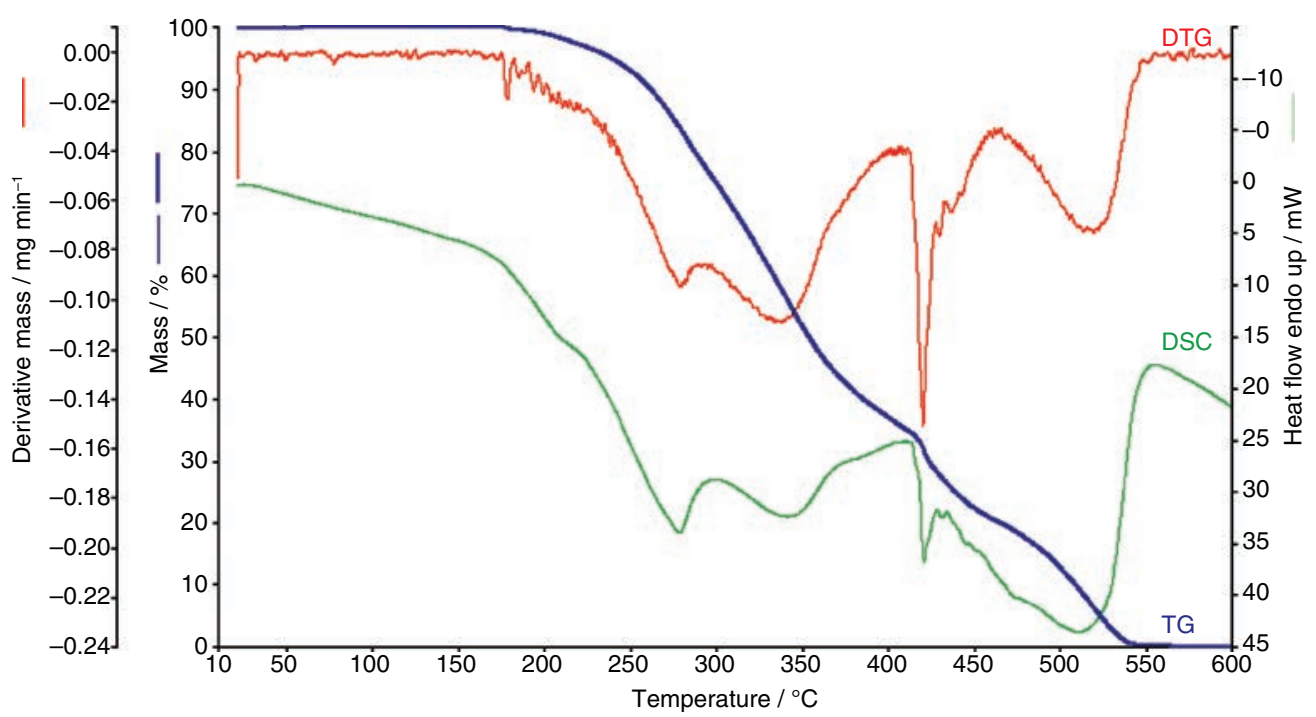

Figure 2. Thermoanalytical (TG, DTG and DSC) curves of sunflower oil enriched in carotenoids after extraction of dry tomato waste.

mass while the control oil lost only $1.4 \%$ of its mass (Figure 3). The first step was the exothermic loss in the volatile compounds with low molecular weight, for the sunflower oil the de-volatilization process started at $182{ }^{\circ} \mathrm{C}$ while for the oil enriched in carotenoids at $165^{\circ} \mathrm{C}$.

The heat released in each decomposition/combustion step depends on the oil. Thus, in the de-volatilization stage, the enthalpy change was $\Delta \mathrm{H}=-3214$ $\mathrm{J} / \mathrm{g}$ for sunflower oil and $\Delta \mathrm{H}=-5723 \mathrm{~J} / \mathrm{g}$ for sunflower oil enriched in carotenoids. For both oils, the de-volatilization process presents two peaks corresponding to the two major decomposition products, at $325.6{ }^{\circ} \mathrm{C}$ and $353^{\circ} \mathrm{C}$ for sunflower oil and at 277.7
${ }^{\circ} \mathrm{C}$ and $340{ }^{\circ} \mathrm{C}$ for sunflower oil after tomato waste extraction.

Differences were also recorded in the decomposition stage of the resinification compounds (resulting after the first stage of decomposition) when the exothermic effects are $\Delta \mathrm{H}=-6153 \mathrm{~J} / \mathrm{g}$ in the sunflower oil and $\Delta \mathrm{H}=-5937 \mathrm{~J} / \mathrm{g}$ in the sunflower oil enriched in carotenoids following extraction, although the peaks are reached at similar values of temperature $\left(423{ }^{\circ} \mathrm{C}\right.$ and $421{ }^{\circ} \mathrm{C}$, respectively). The extraction of compounds in the oil from dry tomato waste resulted in a decrease in the oxidation onset temperature from $263.72{ }^{\circ} \mathrm{C}$ to $221.04{ }^{\circ} \mathrm{C}$. These results are well correlated with 


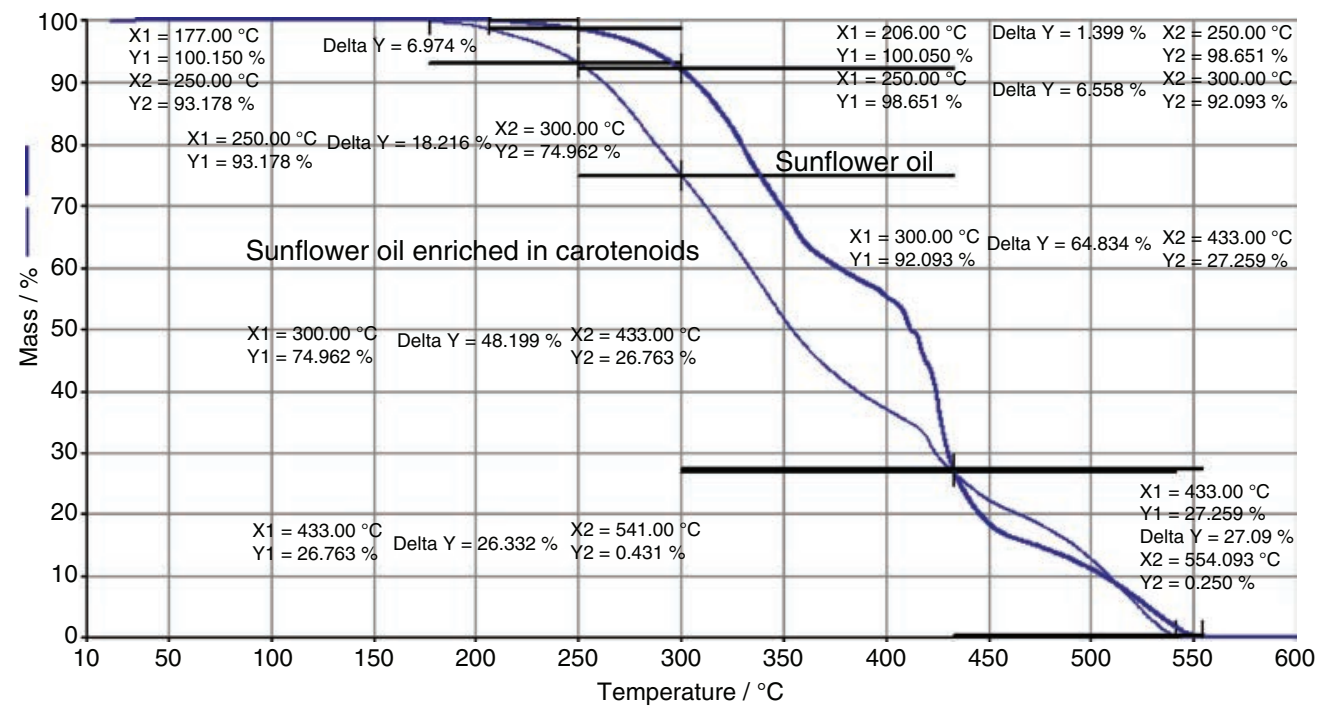

FIGURE 3. TG curves of control sunflower oil and sunflower oil enriched in carotenoids after extraction of dry tomato waste.

those obtained by the Rancimat method, suggesting once more that the compounds extracted from dry tomato waste, including carotenoids, exert a pro-oxidant effect and cause a decrease in the thermal oxidative stability of the extra virgin sunflower oil.

\subsection{Color}

Tables 1-3 list the levels of CIELab indices ( $\mathrm{L}^{*}$, $\left.a^{*}, b^{*}\right)$ for the oils obtained in each experiment. The extraction of dry tomato waste significantly influenced the color parameters of the oils $(\mathrm{p}<$ $0.05)$. Lightness $\left(\mathrm{L}^{*}\right)$ is the attribute related to the transmission of the light ranging from 0 (black) to 100 (white). L* ranged from 72.2 to 78.8 in the present study. The $\mathrm{L}$ values increased by increasing dry tomato waste concentration up to $2.5 \%$ or $5 \%$ (depending on the oil) and decreased afterward; therefore the extraction of high concentrations lead to the darkening of the oils (Table 3 ). The $a^{*}$ values increased (with the exception of extra virgin olive oil) while the $b^{*}$ values decreased after UAE of 5\% tomato waste (Table 1), meaning more red and less yellow, respectively, changes that could be attributed to the extraction of carotenoids, predominantly the red lycopene, in the oils.

\section{CONCLUSIONS}

Carotenoids were extracted in oils in significant amounts from tomato waste, with the highest amount from extraction by soaking for 7 days but ultrasound-assisted extraction and microwaveassisted extraction for 50 minutes proved also to be effective in extracting carotenoids and, at the same time, much faster. The carotenoid content of the oils increased significantly by increasing the incorporation of dry tomato waste.

In some oils the extraction of dry tomato waste improved their oxidative and thermal stability while in others it caused an increase in the peroxide value and a decrease in the induction time as determined by the Rancimat method. In most oils the extraction resulted in a slight but significant decrease in radical scavenger activity. In extra virgin sunflower oil, the extraction of dry tomato waste resulted in a decrease in the oxidation onset temperature from $263.72{ }^{\circ} \mathrm{C}$ to $221.04{ }^{\circ} \mathrm{C}$ as determined by the DSC analysis. For this oil, the results obtained using Rancimat and DSC methods appeared to be consistent, proving a pro-oxidant effect of the compounds extracted from dry tomato waste. The extraction of dry tomato waste in vegetable oil may result in a colored functional oil that could be a potential source of carotenoids and other bioactive compounds.

\section{ACKNOWLEDGMENTS}

This work was supported by a grant from the Romanian National Authority for Scientific Research and Innovation, CNCS/CCCDI - UEFISCDI, project number PN-III-P2-2.1-BG-2016-0019, within PNCDI III.

\section{REFERENCES}

Benakmoum A, Abbeddou S, Ammouche A, Kefalas P, Gerasopoulos D. 2008. Valorisation of low quality edible oil with tomato peel waste. Food Chem. 110, 684-690. https://doi.org/10.1016/j.foodchem.2008.02.063

Bouayed J, Bohn T. 2010. Exogenous antioxidants - Doubleedged swords in cellular redox state: Health beneficial effects at physiologic doses versus deleterious effects at 
high doses. Oxid. Med. Cell. Longev. 3, 228-237. https:// doi.org/10.4161/oxim.3.4.12858

Cheung SCM, Szeto YT, Benzie IFF. 2007. Antioxidant protection of edible oils. Plant Food Hum. Nutr. 62, 39-42. https://doi.org/10.1007/s11130-006-0040-6

Choe E, Min DB. 2006. Mechanisms and factors for edible oil oxidation. Compr. Rev. Food Sci. F 5, 169-186. https://doi. org/10.1111/j.1541-4337.2006.00009.x

Fanciullino AL, Dhuique-Mayer C, Luro F, Casanova J, Morillon R, Ollitrault P. 2006. Carotenoid diversity in cultivated citrus is highly influenced by genetic factors. J. Agr. Food Chem. 54, 4397-4406. https://doi.org/10.1021/ jf0526644

Fiedor J, Burda K. 2014. Potential role of carotenoids as antioxidants in human health and disease. Nutrients 6, 466-488. https://doi.org/10.3390/nu6020466

Gopala Krishna AG, Khatoon S, Babylatha R. 2005. Frying performance of processed rice bran oils. J. Food Lipids 12, 1-11. https://doi.org/10.1111/j.1745-4522.2005.00001.x

Gouveia L, Nobre BP, Marcelo FM, Mrejen S, Cardoso MT, Palavra AF, Mendes RL. 2007. Functional food oil colored by pigments extracted from microalgae with supercritical CO2. Food Chem. 101, 717-723. https://doi.org/10.1016/j. foodchem.2006.02.027

Hassanein MM, El-Shami SM, El-Mallah MH. 2003. Changes occurring in vegetable oils composition due to microwave heating. Grasas Aceites 54, 343-349. https://doi. org/10.3989/gya.2003.v54.i4.219

Huang W, Xue A, Niu H, Jia Z, Wang JW. 2009. Optimised ultrasonic-assisted extraction of flavonoids from Folium eucommiae and evaluation of antioxidant activity in multitest systems in vitro. Food Chem. 114, 1147-1154. https:// doi.org/10.1016/j.foodchem.2008.10.079

Jiménez P, García P, Bustamante A, Barriga A, Robert P. 2017. Thermal stability of oils added with avocado (Persea americana cv. Hass) or olive (Olea europaea cv. Arbequina) leaf extracts during the French potatoes frying. Food Chem. 221, 123-129. https://doi.org/10.1016/j.foodchem.2016.10.051

Juliano C, Cossu M, Alamanni MC, Piu L. 2005. Antioxidant activity of gamma-oryzanol: Mechanism of action and its effect on oxidative stability of pharmaceutical oils. Int. J. Pharmaceut. 299, 146-154. https://doi.org/10.1016/j. ijpharm.2005.05.018

Jung MY, Min DB. 1990. Effects of $\alpha-, \gamma$-, and $\delta$-tocopherols on oxidative stability of soybean oil. J. Food Sci. 55, 1464-1465. https://doi.org/10.1111/j.1365-2621.1990.tb03960.x

Kalantzakis G, Blekas G, Pegklidou K, Boskou D. 2006. Stability and radical scavenging activity of heated olive oil and other vegetable oils. Eur. J. Lipid Sci. Tech. 108, 329-335. https://doi.org/10.1002/ejlt.200500314

Katsoyannos E, Gortzi O, Chatzilazarou Ar, Athanasiadis V, Tsaknis J, Lalas S. 2012. Evaluation of the suitability of low hazard surfactants for the separation of phenols and carotenoids from red-flesh orange juice and olive mill waste water using cloud point extraction. J. Sep. Sci. 35, 2665-2670. https://doi.org/10.1002/jssc.201200356

Lalas S, Gortzi O, Tsaknis J, Sflomos K. 2007. Irradiation effect on oxidative condition and tocopherol content of vegetable oils. Int. J. Mol. Sci. 8, 533-540.

Lalas S, Tsaknis J. 2002. Extraction and identification of natural antioxidant from the seeds of Moringa oleifera tree variety of Malawi. J. Am. Oil. Chem. Soc. 79, 677-683. https://doi. org/10.1007/s11746-002-0542-2
Li Y, Fabiano-Tixier AS, Tomao V, Cravotto G, Chemat F. 2013. Green ultrasound-assisted extraction of carotenoids based on the bio-refinery concept using sunflower oil as an alternative solvent. Ultrason. Sonochem. 20, 12-18. https://doi. org/10.1016/j.ultsonch.2012.07.005

Lianfu Z, Zelong L. 2008. Optimization and comparison of ultrasound/microwave assisted extraction (UMAE) and ultrasonic assisted extraction (UAE) of lycopene from tomatoes. Ultrason. Sonochem. 15, 731-737. https://doi. org/10.1016/j.ultsonch.2007.12.001

Malheiro R, Casal S, Lamas H, Bento A, Pereira JA. 2012. Can tea extracts protect extra virgin olive oil from oxidation during microwave heating? Food Res. Int. 48, 148-154. https://doi.org/10.1016/j.foodres.2012.03.005

Martínez ML, Penci MC, Ixtaina V, Ribotta PD, Maestri D. 2013. Effect of natural and synthetic antioxidants on the oxidative stability of walnut oil under different storage conditions. Food Sci. Technol. 51, 44-50. https://doi. org/10.1111/j.1750-3841.2008.00979.x

Mirabella N, Castellani V, Sala S. 2014. Current options for the valorization of food manufacturing waste: a review. J. Clean. Prod. 65, 28-41. https://doi.org/10.1016/j. jclepro.2013.10.051

Moure A, Cruz JM, Franco D, Domínguez JM, Sineiro J, Domínguez H, Núñez MJ, Parajó JC. 2001. Review: Natural antioxidants from residual sources. Food Chem. 72, 145-171. https://doi.org/10.1016/S0308-8146(00) 00223-5

Shixian Q, Dai Y, Kakuda Y, Shi J, Mittal G, Yeung D, et al. 2005. Synergistic anti-oxidative effects of lycopene with other bioactive compounds. Food Rev. Int. 21, 295-311. https://doi.org/10.1080/FRI-200061612

Taungbodhitham AK, Jones GP, Wahlqvist ML, Briggs DR. 1998. Evaluation of extraction method for the analysis of carotenoids in fruits and vegetables. Food Chem. 63, 577-584. https://doi.org/10.1016/S03088146(98)00011-9

Toor RK, Savage GP. 2005. Antioxidant activity in different fractions of tomatoes. Food Res. Int. 38, 487-494. https:// doi.org/10.1016/j.foodres.2004.10.016

Tsaknis J, Lalas S. 2005. Extraction and identification of natural antioxidant from Sideritis euboea (mountain tea). J. Agric. Food Chem. 53, 6375-6381. https://doi.org/10.1021/jf04 79261

Vagi E, Simandi B, Vasarhelyine KP, Daood H, Kery A, Doleschall F, Nagy B. 2007. Supercritical carbon dioxide extraction of carotenoids, tocopherols and sitosterols from industrial tomato by-products. $J$. Supercrit. Fluid 40, 218-226. https://doi.org/10.1016/j. supflu.2006.05.009

Zhao L, Zhao G, Chen F, Wang Z, Wu J, Hu X. 2006. Different effects of microwave and ultrasound on the stability of (all-E)-Astaxanthin. J. Agric. Food Chem. 54, 8346-8351. https://doi.org/10.1021/jf061876d

Zhang Y, Yang L, Zu Y, Chen X, Wang F, Liu F. 2010. Oxidative stability of sunflower oil supplemented with carnosic acid compared with synthetic antioxidants during accelerated storage. Food Chem. 118, 656-662. https://doi. org/10.1016/j.foodchem.2009.05.038

Zuorro A, Lavecchia R, Medici F, Piga L. 2013. Enzyme-assisted production of tomato seed oil enriched with lycopene from tomato pomace. Food Bioprocess Tech. 6, 3499-3509. https://doi.org/10.1007/s11947-012-1003-6 